\title{
Voltammetric Determination of Bisphenol A Based on Its Anodic Deposition at Chitosan-Graphene Modified Glassy Carbon Electrode under UV Irradiation
}

\author{
Zhihong Yan, Bo Fu, Jincheng Chen, Tailin Liu, Kang Li ${ }^{*}$ \\ College of pharmacy, Guangdong Pharmaceutical University, Guangzhou 510006, PR China. \\ *E-mail: likang229@aliyun.com
}

doi: $10.20964 / 2018.02 .29$

Received: 19 October 2017 / Accepted: 6 December 2017 / Published: 28 December 2017

\begin{abstract}
Bisphenol A (BPA) was successfully electrodeposited on glassy carbon electrode modified with the chitosan-graphene (Chit-GR/GCE) by multiple sweep voltammetry under ultraviolet (UV) irradiation. The experimental conditions of the BPA deposits and the probable oxidation mechanism were investigated. Two oxidation peaks (peakII $=0.12 \mathrm{~V}$, peakIII $=0.20 \mathrm{~V}$ ) appeared in a suitable potential range of $0.0 \mathrm{~V}$ and $0.2 \mathrm{~V}$ at the Chit-GR/GC eletrode in the presence of UV light, and it could be seen that the oxidation peak current increased with the increase of UV irradiation time. The emerging peakIII was reported firstly in the work, which showed that the Chit-GR modified electrode had catalytic activity on the oxidation of BPA. Based on the oxidation peak (peakIII) of BPA oxidative porducts on the Chit-GR/GC electrode under UV irradiation, the electrochemical sensor was fabiracated for determination of BPA. The calibration curve was obtained in the range of 5.0 to 200.0 $\mu \mathrm{M}$ with the limit of detection of $0.34 \mu \mathrm{M}(\mathrm{S} / \mathrm{N}=3)$ and the response sensitivity of $0.33 \mu \mathrm{A} \mu \mathrm{M}^{-1}$, which was higher than those of the method of determining BPA based on the direct oxidtation of BPA $\left(0.98 \mu \mathrm{M}(\mathrm{S} / \mathrm{N}=3), 0.12 \mu \mathrm{A} \mu \mathrm{M}^{-1}\right)$. It was applied successfully for determination of BPA in lake, soil and plastic bottle samples. The new strategy, based on anodic electrodeposition and photocatalytic oxidation of BPA oxidation porducts, was provided for determination of BPA under UV irradiation. It was green, evironmental and effective.
\end{abstract}

Keywords: Bisphenol A, Anodic deposition, Graphene, Ultraviolet irradiation

\section{$\underline{\text { FULL TEXT }}$}

(C) 2018 The Authors. Published by ESG (www.electrochemsci.org). This article is an open access article distributed under the terms and conditions of the Creative Commons Attribution license (http://creativecommons.org/licenses/by/4.0/). 